\title{
Do potent immobilising-opioids induce different physiological effects in impala and blesbok?
}

\begin{tabular}{|c|c|}
\hline $\begin{array}{l}\text { Authors: } \\
\text { Silke Pfitzer }{ }^{1,2} \\
\text { Michael Laure } \\
\text { Liesel Laubsch } \\
\text { Jacobus P. Raa } \\
\text { Kristin Warren } \\
\text { Rebecca Vaug } \\
\text { Leith R.C. Mey }\end{array}$ & 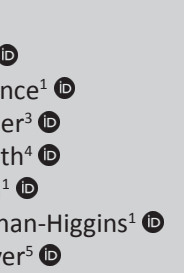 \\
\hline $\begin{array}{l}\text { Affiliations: } \\
{ }^{1} \text { School of Vet } \\
\text { Medicine, Col } \\
\text { Health, Engine } \\
\text { Education, Mc } \\
\text { University, Per }\end{array}$ & $\begin{array}{l}\text { erinary } \\
\text { ege of Science, } \\
\text { ering and } \\
\text { urdoch } \\
\text { th, Australia }\end{array}$ \\
\hline $\begin{array}{l}{ }^{2} \text { School of Bio } \\
\text { Environmenta } \\
\text { Faculty of Agri } \\
\text { Natural Scienc } \\
\text { of Mpumalans } \\
\text { South Africa }\end{array}$ & $\begin{array}{l}\text { logy and } \\
\text { I Sciences, } \\
\text { culture and } \\
\text { es, University } \\
\text { sa, Nelspruit, }\end{array}$ \\
\hline $\begin{array}{l}{ }^{3} \text { Department } \\
\text { Science, Unive } \\
\text { Stellenbosch, } \\
\text { South Africa }\end{array}$ & $\begin{array}{l}\text { f Animal } \\
\text { rrsity of } \\
\text { Cape Town, }\end{array}$ \\
\hline $\begin{array}{l}{ }^{4} \text { Wildlife Phar } \\
\text { South Africa ( } \\
\text { River, South A }\end{array}$ & $\begin{array}{l}\text { maceuticals } \\
\text { Dty) Ltd, White } \\
\text { frica }\end{array}$ \\
\hline $\begin{array}{l}{ }^{5} \text { Centre for Ve } \\
\text { Wildlife Studie } \\
\text { Department o } \\
\text { Sciences, Facu } \\
\text { Veterinary Sci } \\
\text { of Pretoria, Pr } \\
\text { South Africa }\end{array}$ & $\begin{array}{l}\text { terinary } \\
\text { s and } \\
\text { f Paraclinical } \\
\text { Ity of } \\
\text { ence, University } \\
\text { etoria, }\end{array}$ \\
\hline $\begin{array}{l}\text { Correspondin } \\
\text { Silke Pfitzer, } \\
\text { silke.pfitzer@i }\end{array}$ & $\begin{array}{l}\text { g author: } \\
\text { cloud.com }\end{array}$ \\
\hline $\begin{array}{l}\text { Dates: } \\
\text { Received: } 28 \mathrm{I} \\
\text { Accepted: } 04 \\
\text { Published: } 06\end{array}$ & $\begin{array}{l}\text { Jov. } 2019 \\
\text { May } 2020 \\
\text { Aug. } 2020\end{array}$ \\
\hline Read online: & \\
\hline $\begin{array}{l}\square+2 \\
y^{2}\end{array}$ & $\begin{array}{l}\text { Scan this QR } \\
\text { code with your } \\
\text { smart phone or } \\
\text { mobile device } \\
\text { to read online. }\end{array}$ \\
\hline
\end{tabular}

Authors:

Silke Pfitzer ${ }^{1,2}$

Jacobus P. Raat

Kristin Warren ${ }^{1}$ (D)

becca Vaughan-Higgins ${ }^{1}$

Affiliations:

Health, Engineering and

Education, Murdoch

${ }^{2}$ School of Biology and

Environmental Sciences,

Faculty of Agriculture and

Natural Sciences, University

South Africa

${ }^{3}$ Department of Anima

Science, University of

Stellenbosch, Cape Town,

Vildife Pharmaceuticals

South Africa (Pty) Ltd, White

${ }^{5}$ Centre for Veterinary

Wildlife Studies and

Department of Paraclinical

of Pretoria, Pretoria,

Silke Pfitzer,

silke.pfitzer@icloud.com

Dates:

Accepted: 04 May 2020

Published: 06 Aug 2020

mobile device

to read online.
Potent opioids are known to cause negative alterations to the physiology of immobilised antelope. How these effects differ between species has not been studied. This study aimed to compare time to recumbence and effects of opioid-based immobilisation on the physiology of impala (Aepyceros melampus) and blesbok (Damaliscus pygargus phillipsi). Eight animals of each species were immobilised, with $0.09 \mathrm{mg} / \mathrm{kg}$ etorphine and $0.09 \mathrm{mg} / \mathrm{kg}$ thiafentanil respectively, in a randomised two-way cross-over study. Variables measured and analysed by means of a linear mixed model included time to recumbence, heart rate, respiratory rate, arterial blood pressure, blood gases, lactate and glucose. In blesbok, mean time to recumbence was not significantly different with either drug (2.5 minutes and $2.2 \mathrm{~min}$, respectively), but in impala thiafentanil achieved a shorter time to recumbence $(2.0 \mathrm{~min})$ than etorphine $(3.9 \mathrm{~min})$. Mean heart rates of immobilised impala were within reported physiological limits, but lower in immobilised blesbok when both opioids were used ( 35 beats / $\mathrm{min}$ to 44 beats / $\mathrm{min}$ vs. $104 \pm 1.4$ beats/min resting heart rate). Impala developed severe respiratory compromise and hypoxaemia from both opioids (overall mean $\mathrm{PaO}_{2}$ values ranged from $38 \mathrm{mmHg}$ to $59 \mathrm{mmHg}$ over $30 \mathrm{~min}$ ). In contrast, blesbok developed only moderate compromise. Therefore, significantly different species-specific physiological responses to potent opioid drugs exist in blesbok and impala. Given that these different responses are clinically relevant, extrapolation of immobilising drug effects from one species of African ungulate to another is not recommended.

Keywords: Blesbok; etorphine; immobilisation; impala; opioids; thiafentanil.

\section{Introduction}

When immobilising drugs are developed for use in wild African ungulates, it is often difficult to make dose recommendations owing to the wide variety of species in this group and the lack of reported efficacy studies (Hernandez 2005). When investigating the physiological response to drugs in wild ungulates, domestic species are often used as models (Harthoorn 1967; Heard et al. 1996; Izwan et al. 2018; Meyer et al. 2015; Meyer, Fuller \& Mitchell 2006; O’Dell et al. 2017; Pfitzer et al. 2019a). The domestic animal model approach is usually then followed by the selection of wild ungulate species thought to be representative of the domestic animal. The species most commonly used for this purpose is the impala. Impalas are easily kept in zoo as they are, not classified as threatened and are readily available in the wild and in intensive farming operations in Southern Africa (Harthoorn 1967; Janssen et al. 1993; Meyer et al. 2008; Perrin et al. 2015; Pfitzer et al. 2019b; Zeiler \& Meyer 2017a, 2017b). Looking at the phylogenetic tree of the subfamily of Antilopinae, impala are somewhat removed from other subfamilies commonly captured by immobilisation such as Hippotraginae, which include sable antelope (Hippotragus niger), roan antelope (Hippotragus equinus) and oryx (Oryx gazella); and Alcelaphinae, which include blesbok, two wildebeest species (Connochaetes spp.), hartebeest (Alcelaphus spp.) and tsessebe (Damaliscus spp.) (Chen et al. 2019; Hernandez Fernandez \& Vrba 2005). Impala are considered a difficult species to immobilise (Perrin et al. 2015; Pfitzer et al. 2019b; Zeiler \& Meyer 2017a, 2017b). Their flighty nature and fine body structure can lead to physical injury when they are darted. Furthermore, their physiological response to opioids seems unpredictable and frequent deaths have been reported (Meyer et al. 2010; Perrin et al. 2015; Zeiler \& Meyer 2017a, 2017b). Accordingly, the physiological response of impala to opioids might not necessarily be representative and comparable to many other antelope species. In contrast, blesbok seem to have a more predictable response to opioids and are considered an easy species to immobilise (Pfitzer et al. 2019b). Blesbok,

How to cite this article: Pfitzer, S., Laurence, M., Laubscher, L., Raath, J.P., Warren, K., Vaughan-Higgins, R. et al., 2020, 'Do potent immobilising-opioids induce different physiological effects in impala and blesbok?, Journal of the South African Veterinary Association 91(0), a2038. https://doi.org/10.4102/jsava.v91i0.2038

Copyright: @ 2020. The Authors. Licensee: AOSIS. This work is licensed under the Creative Commons Attribution License. 
belonging to the subfamily Alcelaphinae, are phylogenetically more closely related to many African antelope species (Chen et al. 2019; Hernandez Fernandez \& Vrba 2005). Blesbok were chosen for this study because, like impala, blesbok are seasonal breeders, are readily available in Southern Africa and are not threatened (Furstenburg 2016a, 2016b). Blesbok also live in a herd and can be housed in captivity in groups. As both sexes have horns, long-term confinement can be a challenge as fighting and injuries occur (Pfitzer et al. 2019b). These are some of the reasons why blesbok are not commonly kept in zoo collections and have not been commonly used for ex-situ wildlife research. Only recently have several capturerelated research projects been carried out using blesbok (Du Plessis 2018; Fitte 2017; Sawicka et al. 2014).

The aim of this experiment was to compare the physiological responses of impala and blesbok to two potent opioids which are commonly used to immobilise wild antelope species. It was hypothesised that the opioids will affect each species differently and that those effects are of clinical relevance.

\section{Materials and methods}

This study was part of a larger study evaluating the effects of etorphine and thiafentanil in blesbok and impala respectively.

Eight wild-captured female impala weighing $37 \mathrm{~kg}$ (standard error [SE] 2) and eight wild-captured female blesbok weighing $58 \mathrm{~kg}$ (SE 1.45) were selected for this experiment and held at the Wildlife Pharmaceuticals Wildlife Research Facility,

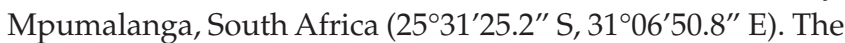
research animals were all adult females of similar size and in good health in order to minimise variability that could confound the results. Horns of the blesbok were piped with plastic pipes to prevent horn injuries commonly encountered in captive blesbok.

The wildlife enclosures were constructed according to national guidelines and consisted of several compartments (SABS 2004). The animals were held separated by species and in groups of four. After an initial adjustment period of 2 weeks post-delivery, the animals were immobilised, marked, weighed and subjected to a veterinary health examination one week before the trial.

The immobilising drugs etorphine (Captivon, $9.8 \mathrm{mg} / \mathrm{mL}$, Wildlife Pharmaceuticals [Pty] Ltd, South Africa) and thiafentanil (Thianil, $10 \mathrm{mg} / \mathrm{mL}$, Wildlife Pharmaceuticals [Pty] Ltd, South Africa) were administered intramuscularly via remote injection by darting into the gluteus muscles. Darting equipment consisted of a gas-powered dart projector (X-Caliber; Pneu-Dart Inc., Pennsylvania, United States [US]) combined with $1 \mathrm{~mL}$ P-type Pneu-Darts with $1.9 \mathrm{~cm}$ barbed needles (Pneu-Dart Inc., Pennsylvania, US). Animals were darted on two separate occasions with a wash-out period of two weeks between each occasion. Each antelope received both drug treatments which were allocated to animals at random in a two-way cross-over design. One treatment consisted of $0.09 \mathrm{mg} / \mathrm{kg}$ etorphine and the other treatment consisted of $0.09 \mathrm{mg} / \mathrm{kg}$ thiafentanil. The immobilisation efficacy of these doses had been determined in a previous study (Pfitzer et al. 2019b).

As soon as an animal became recumbent and could be approached, it was blindfolded and cotton wool was inserted into its ears to minimise external stimuli. The animal was then placed onto a stretcher in sternal recumbency with its head held up and nose pointing downwards to ensure patency of the upper airway. It was carried to the monitoring table and kept in this position throughout the monitoring period.

Time to recumbence was measured by means of a stopwatch function on a wristwatch (G-Shock, Casio Computer Co., Ltd., Japan) and defined as time from dart injection to when the animal was recumbent and unable to rise.

Monitoring and recording began at $5 \mathrm{~min}$ after an animal became recumbent and was continued every 5 min until $40 \mathrm{~min}$ post-recumbence. Rectal body temperature was measured in ${ }^{\circ} \mathrm{C}$ by means of a modified handheld digital thermometer (Hanna Checktemp 1, Hanna Instruments [Pty] Ltd, Nebraska, US). The environmental temperature was measured by the Weather ${ }^{+}$Bluetooth Sensor (Oregon Scientific, Oregon, US). Barometric pressure was measured by the epoc portable blood gas analyser (epoc Blood Analysis System, Epocal, Ontario, Canada). This instrument was also used to analyse arterial blood $\mathrm{pH}$, glucose in $\mathrm{mmol} / \mathrm{L}$, lactate in $\mathrm{mmol} / \mathrm{L}$, arterial partial pressure of carbon dioxide $\left(\mathrm{PaCO}_{2}\right)$ in $\mathrm{mmHg}$ at $37^{\circ} \mathrm{C}$ and arterial partial pressure of oxygen $\left(\mathrm{PaO}_{2}\right)$ in $\mathrm{mmHg}$ at $37{ }^{\circ} \mathrm{C}$. The respiratory rate (breaths/minute) was measured manually by means of visual observation of chest expansions and auscultation with a stethoscope for $1 \mathrm{~min}$ (Littmann Classic II, $3 \mathrm{M}^{\mathrm{TM}}$, Minnesota, US). Heart rate (beats/minute) was also measured with a stethoscope in the same manner as respiratory rate. Systolic arterial pressure (SAP) in $\mathrm{mmHg}$, diastolic arterial pressure (DAP) in mmHg and mean arterial pressure (MAP) in $\mathrm{mmHg}$ were determined by means of an intra-arterial blood pressure measurement at the auricular (Arteria auricularis) or pedal arteries (A. digitalis). A Deltran II pressure transducer (Utah Medical, Utah, US) connected to an IntraTorr blood pressure monitor (IntraTorr, IntraVitals, United Kingdom [UK]) were used for this purpose. The transducer was placed near the scapulohumeral joint (heart base) of the animal. Arterial blood was drawn anaerobically in a heparinised blood gas syringe (BD A-Line, Becton, Dickinson and Company, UK) and subjected to blood gas analysis within $5 \mathrm{~min}$ using the epoc portable blood gas analyser with epoc BGEM test cards (BGEM Smart Cards, Epocal, Ontario, Canada). Samples were collected at the frequencies of 5, 10, 15, 20 and 30 min after recumbence. The alveolar-arterial oxygen (A-a) gradient was calculated according to the publication by Meyer et al. (2010). The A-a gradient was calculated for an open system (constant pressure) from the formula:

$\mathrm{FiO}_{2}\left(\mathrm{~Pb}-\mathrm{PH}_{2} \mathrm{O}\right)-\mathrm{PaCO}_{2}-\mathrm{PaO}_{2}$,

[Eqn 1] 
where $\mathrm{FiO}_{2}$ is the fractional inspired oxygen (0.209), $\mathrm{Pb}$ is the measured barometric pressure $(\mathrm{mmHg})$ and $\mathrm{PH}_{2} \mathrm{O}$ is the water vapour pressure of saturated air in the alveoli. $\mathrm{PH}_{2} \mathrm{O}(\mathrm{mmHg})$ was calculated as $4.58 \mathrm{e}\{(17.27 \mathrm{~Tb}) /(237.3+\mathrm{Tb})\}$, where $\mathrm{Tb}$ is the body temperature. The researchers assumed that the partial pressure of $\mathrm{CO}_{2}$ in the alveoli was equal to the arterial partial pressure of $\mathrm{CO}_{2}$. A mean $\mathrm{PaO}_{2}<80 \mathrm{mmHg}$ was defined as moderate hypoxaemia whilst a mean $\mathrm{PaO}_{2}$ of $<60 \mathrm{mmHg}$ was defined as severe hypoxaemia.

After the 40-min monitoring period was over, the immobilisation of each animal was reversed with intravenous naltrexone (Trexonil, $50 \mathrm{mg} / \mathrm{mL}$, Wildlife Pharmaceuticals [Pty] Ltd, South Africa), injected at a ratio of $20 \mathrm{mg}$ naltrexone to $1 \mathrm{mg}$ etorphine and $10 \mathrm{mg}$ naltrexone per $1 \mathrm{mg}$ thiafentanil.

The partial reversal agent butorphanol (Butonil $50 \mathrm{mg} / \mathrm{mL}$, Wildlife Pharmaceuticals [Pty] Ltd, South Africa) as well as naltrexone were kept on hand to partially reverse or fully reverse the immobilisation in case of adverse anaesthetic events, such as potentially life-threatening apnoea of a duration exceeding $1.5 \mathrm{~min}$. No animals needed this treatment.

Ambient temperatures during the blesbok experiments with etorphine were $24.9{ }^{\circ} \mathrm{C}$ (SE 4.99) and during thiafentanil treatment they were $24.3{ }^{\circ} \mathrm{C}$ (SE 1.55). The mean barometric pressure was 698 (SE 1.80) $\mathrm{mmHg}$

For the impala, ambient temperatures measured during the etorphine treatment were $20.7{ }^{\circ} \mathrm{C}$ (SE 4.52) and during thiafentanil treatment they were $21.9^{\circ} \mathrm{C}(\mathrm{SE} 4.68)$. The mean barometric pressure was 697 (SE 2.34) $\mathrm{mmHg}$.

\section{Data analysis}

Analyses were performed with Genstat Version 17 (VSN International, UK) to determine whether or not there was a species-specific difference between the two opioids on the physiological variables of interest. A linear mixed model was fitted to the monitored physiological variables and immobilisation score. Each fixed model included the following factors: species-specific effects, treatment effects, species-specific by treatment interactions, the effects of time after recumbence, and interactions between time after recumbence and species and treatment. The random model included terms for animal, animal by treatment and animal by treatment by minutes after recumbence. The residual variance or covariance model included correlations between measurements made on the same animal for a specific treatment and different variances for each animal.

Time to recumbence was analysed using a linear mixed model which included species-specific effects, treatment effects and their interaction in the fixed model, and animal by treatment effects in the random model. The residual variance model included different variances for each species.

Non-significant random effects and covariances were removed from the model before the significance of fixed effects was assessed. Post-analysis residual plots were examined to confirm that the assumptions required for a linear model were met. When interpreting results, only effects that included a species-specific interaction with treatment were of interest as these indicated differences in the species' response to treatment. A $p$-value of less than 0.05 was considered significant. Post hoc comparisons were made for significant species-specific interactions using a 5\% least significant difference ( $5 \%$ LSD). In figures, the $5 \%$ LSD is used to illustrate whether or not differences between the species means are significant. Any difference larger than the $5 \%$ LSD is considered a significant result. Results are presented as mean and standard error (SE).

\section{Ethical considerations}

Ethical approval to conduct the study was obtained from the Murdoch University, ethical clearance number R 3039/18.

\section{Results}

Mean rectal temperatures of blesbok during the monitoring period varied between $39.0{ }^{\circ} \mathrm{C}$ and $39.2{ }^{\circ} \mathrm{C}$ (SE 0.08) with the etorphine treatment, and between $38.9^{\circ} \mathrm{C}$ and $39.0^{\circ} \mathrm{C}$ (SE 0.08) with the thiafentanil treatment. In impala, mean rectal temperatures during etorphine immobilisation varied from $38.7^{\circ} \mathrm{C}$ to $39.1{ }^{\circ} \mathrm{C}$ (SE 0.12) and with the thiafentanil treatment rectal temperatures varied from $38.8^{\circ} \mathrm{C}$ to $39.2^{\circ} \mathrm{C}$ (SE 0.12).

There was a significant species by treatment interaction for time to recumbence $(p=0.009)$. In blesbok, there were no significant differences between treatments for mean time to recumbence. The mean time to recumbence in blesbok immobilised with etorphine was $2.5 \mathrm{~min}$ (SE 0.14) and with thiafentanil, $2.2 \mathrm{~min}$ (SE 0.14). This finding was in contrast to impala, where the mean time to recumbence was faster $(p=0.007)$, with the thiafentanil treatment at $2.0 \mathrm{~min}$ (SE 0.17) compared to etorphine treatment at $3.9 \mathrm{~min}$ (SE 0.19).

There was a significant interaction of species, treatment and time $(p=0.007)$ for heart rate. Blesbok, when treated with either opioid, developed much lower overall mean heart rates (etorphine mean $=37$; thiafentanil mean $=43$ beats $/ \mathrm{min}$ [SE 1.4]) compared to impala etorphine mean $=98$; thiafentanil mean $=109$ beats $/ \mathrm{min}$ [SE 4.0]). The heart rate of impala, when treated with etorphine, started with a mean of 133 beats / $\mathrm{min}$ at $5 \mathrm{~min}$ but dropped within $30 \mathrm{~min}$ to 82 beats/min (SE 4.5). The range of heart rate actually measured in impala during these experiments varied from 52 beats/min to 190 beats/min. This considerable change over time and variability was not present in blesbok (Figure 1a).

There was a significant species by treatment by time interaction for mean arterial pressure (MAP) $(p=0.007)$.

Mean arterial pressure was elevated in both species with either drug throughout the monitoring period but more so when thiafentanil was administered $(p<0.001)$. In blesbok, the mean MAP was $128 \mathrm{mmHg}$ and $136 \mathrm{mmHg}$ (SE 2.4) with etorphine and thiafentanil respectively. In impala, the mean 


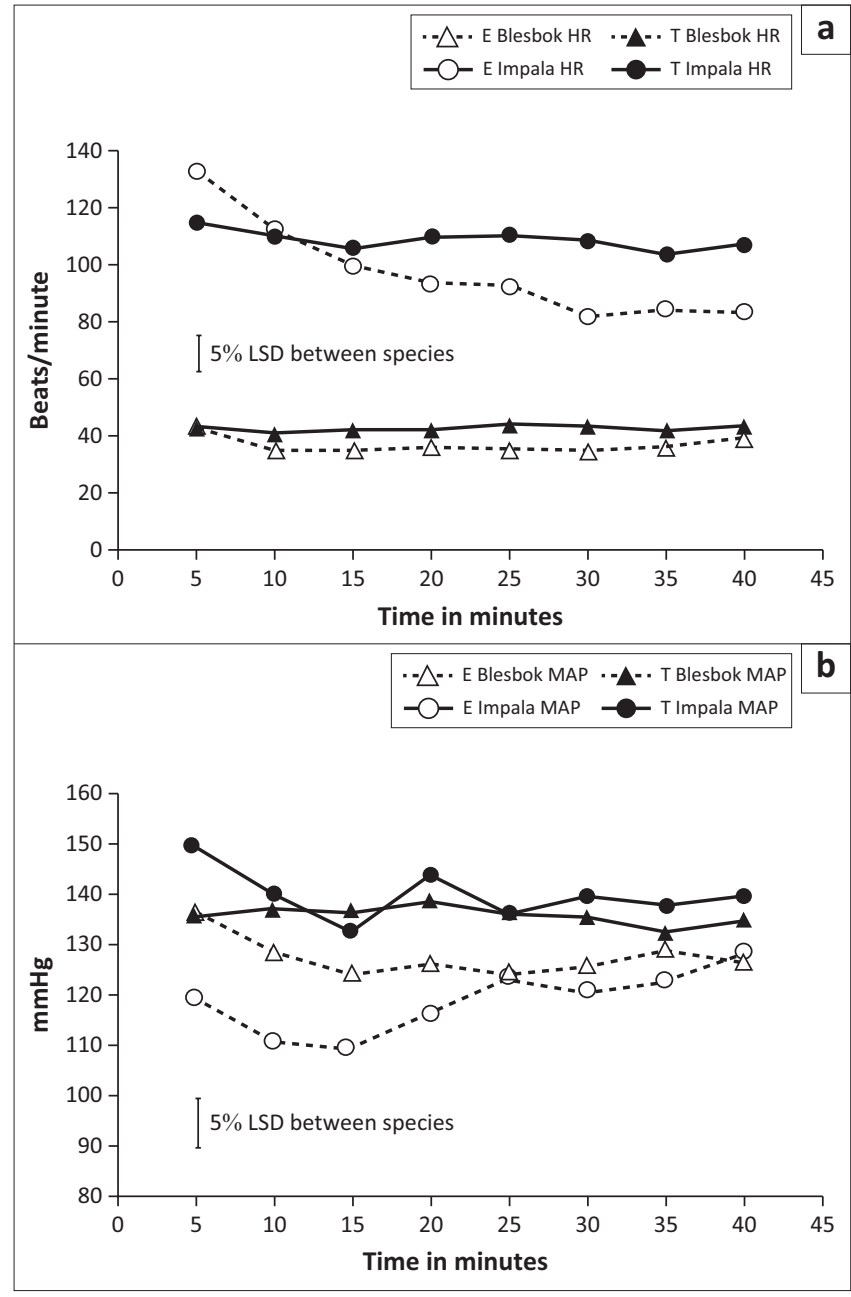

E, ethorphine; T, thiafentanil; MAP, mean arterial pressure; HR, heart rate; LSD, least significant difference.

FIGURE 1: Heart rate (HR) in beats/minute (a) and mean arterial pressure (MAP) in $\mathrm{mmHg}$ (b) over time (minutes) of blesbok (Damaliscus pygargus phillipsi) and impala (Aepyceros melampus) immobilised with $0.09 \mathrm{mg} / \mathrm{kg}$ etorphine (E) or thiafentanil (T) respectively. Time was measured from when an animal became recumbent as a result of the immobilisation.

MAP was $119 \mathrm{mmHg}$ with etorphine and $140 \mathrm{mmHg}$ (SE 2.2) with thiafentanil (Figure 1b).

There was a species by treatment interaction $(p=0.036)$ as well as a species by time interaction $(p<0.001)$ for respiratory rate. Blesbok immobilised with thiafentanil over the entire monitoring period showed the highest respiratory rate. Impala, when immobilised with either opioid, showed very low respiratory rates especially in the first $15 \mathrm{~min}$ (Figure 2a). Twenty per cent of impala suffered from initial induction apnoea when immobilised with thiafentanil. Induction apnoea was defined as no breath taken for over a minute. The apnoea corrected itself within this time frame and the animals were just monitored and stimulated by pulling the tongue or pinching the nasal septum.

There was a species by treatment by time interaction for $\mathrm{PaCO}_{2}(p=0.027)$. For the mean $\mathrm{PaCO}_{2}$ a significant species difference could also be observed as $\mathrm{PaCO}_{2}$ values were higher in impala compared to blesbok with both treatments $(p=0.002)$ (Figure 2a).

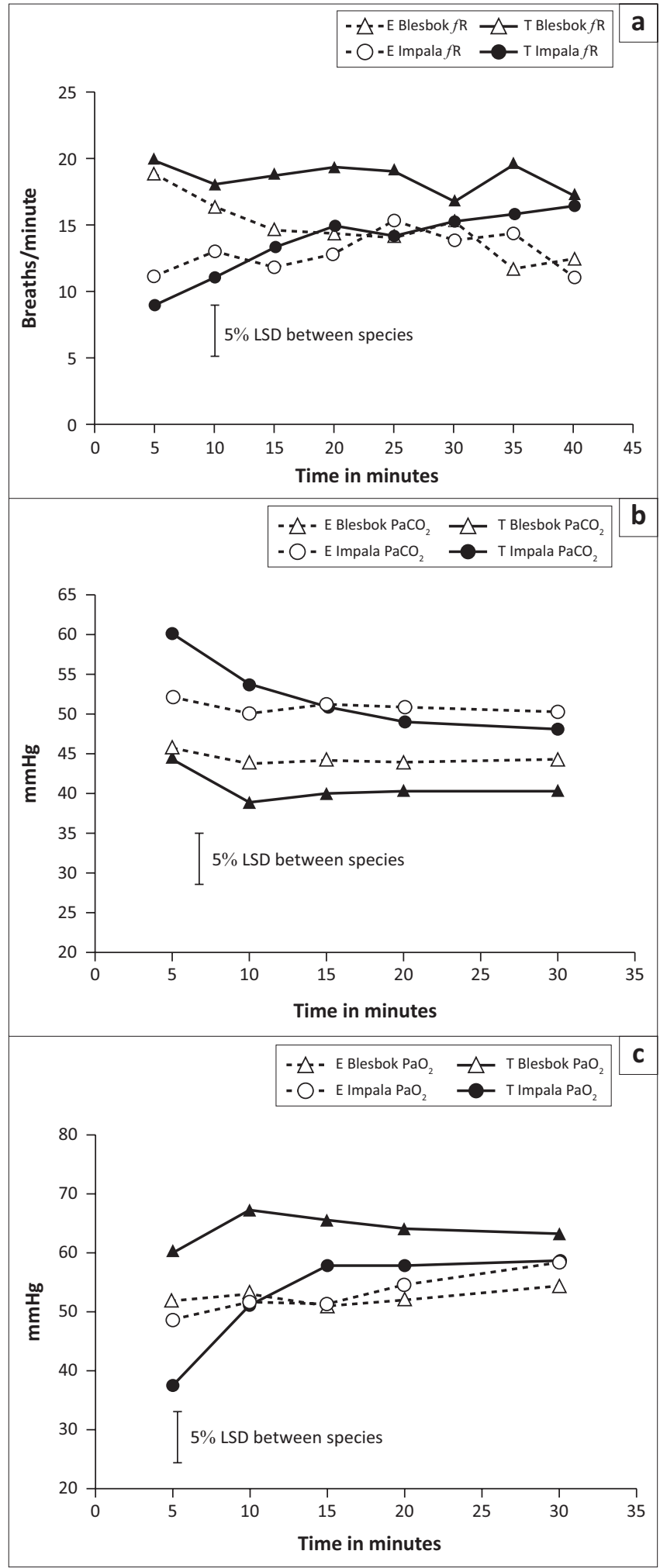

E, ethorphine; T, thiafentanil; LSD, least significant difference.

FIGURE 2: Respiratory rate in breaths/minute (a), $\mathrm{PaCO}_{2}$ (b) and $\mathrm{PaO}_{2}$ (c) in $\mathrm{mmHg}$ over time (minutes) of blesbok (Damaliscus pygargus phillipsi) and impala (Aepyceros melampus) immobilised with $0.09 \mathrm{mg} / \mathrm{kg}$ etorphine (E) or thiafentanil $(T)$ respectively. Time was measured from when an animal became recumbent as a result of the immobilisation.

There was a significant species by treatment interaction for $\mathrm{PaO}_{2}(p=0.006)$. Thiafentanil treatment of impala in the beginning elicited an extremely low $\mathrm{PaO}_{2}$ of $38 \mathrm{mmHg}$, which then improved within the first $10 \mathrm{~min}$ and reached $59 \mathrm{mmHg}$ 


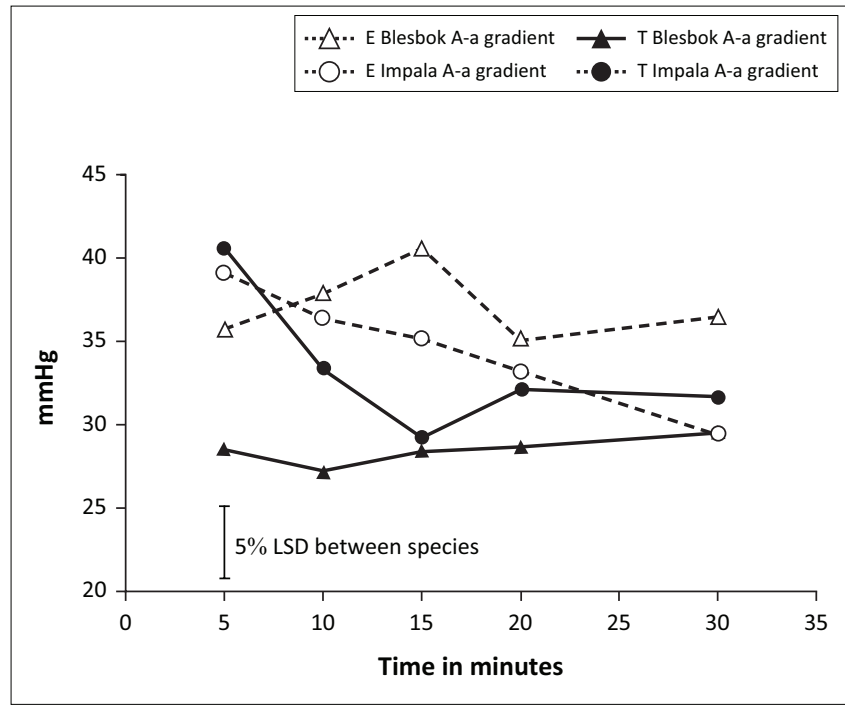

$E$, ethorphine; $T$, thiafentanil; LSD, least significant difference.

FIGURE 3: A-a gradient in $\mathrm{mmHg}$ over time (minutes) of blesbok (Damaliscus pygargus phillipsi) and impala (Aepyceros melampus) immobilised with $0.09 \mathrm{mg} / \mathrm{kg}$ etorphine $(E)$ or thiafentanil $(T)$ respectively. Time was measured from when an animal became recumbent as a result of the immobilisation.

(SE 1.7) after $30 \mathrm{~min}$. Blesbok, in contrast, experienced milder hypoxaemia with thiafentanil throughout the monitoring period with mean $\mathrm{PaO}_{2}$ values ranging from $61 \mathrm{mmHg}$ to $68 \mathrm{mmHg}$ (SE 1.5) (Figure 2b).

There was a species by treatment interaction $(p=0.009)$ for the A-a gradient. In blesbok, the A-a gradient was significantly lower when animals were treated with thiafentanil (mean = $28 \mathrm{mmHg}$ [SE 1.0]) compared to etorphine (mean = $37 \mathrm{mmHg}$ [SE 1.0]). This difference between the two opioids was not observed in impala in which the mean A-a gradient measured $34 \mathrm{mmHg}$ and $33 \mathrm{mmHg}$ (SE 0.7) for etorphine and thiafentanil respectively (Figure 3).

There was significant species by treatment interaction for $\mathrm{pH}$ $(p<0.001)$. With either opioid treatment, blesbok had higher arterial $\mathrm{pH}$ values compared to impala (Table 1a).

There was a significant species by time interaction $(p=0.002)$ for lactate concentrations. Impala developed higher lactate values than blesbok, irrespective of the treatment. In both species, lactate values decreased over time (Table 1a).

There was a significant species difference in glucose concentrations $(p<0.001)$; impala developed higher glucose values than blesbok for both opioid treatments. Glucose decreased over time in impala with both treatments, but glucose values did not decrease in blesbok (Table $1 \mathrm{~b}$ ).

\section{Discussion}

Comparing the physiological response to immobilisation between two common antelope species yielded interesting findings. In general, it is apparent that different species respond differently to commonly administered drugs. Specifically, it appeared that blesbok were less subject to
TABLE 1a: Species comparison of arterial blood $\mathrm{pH}$, lactate in $\mathrm{mmol} / \mathrm{L}$ and glucose in $\mathrm{mmol} / \mathrm{L}$ over time and standard error during immobilisation, with etorphine $0.09 \mathrm{mg} / \mathrm{kg}$ and thiafentanil $0.09 \mathrm{mg} / \mathrm{kg}$, of blesbok (Damaliscus pygargus phillipsi) and impala (Aepyceros melampus) respectively.

Variable Species Time after recumbence with etorphine in minutes SE

\begin{tabular}{llcccccc} 
& & $\mathbf{5}$ & $\mathbf{1 0}$ & $\mathbf{1 5}$ & $\mathbf{2 0}$ & $\mathbf{3 0}$ & \\
\cline { 3 - 7 } $\mathrm{pH}$ & Blesbok & $\mathbf{7 . 4 2}$ & $\mathbf{7 . 4 3}$ & 7.43 & 7.44 & 7.44 & 0.005 \\
& Impala & $\mathbf{7 . 3 0}$ & $\mathbf{7 . 3 2}$ & $\mathbf{7 . 3 4}$ & 7.36 & 7.39 & 0.007 \\
\multirow{2}{*}{ Lactate } & Blesbok & 1.4 & 1.1 & 1.0 & 0.9 & 0.7 & 0.22 \\
& Impala & 5.2 & 4.2 & 3.2 & 2.5 & 1.5 & 0.26 \\
\multirow{2}{*}{ Glucose } & Blesbok & 5.3 & 5.2 & 5.1 & 5.0 & 5.1 & 0.11 \\
& Impala & 7.7 & 7.6 & 7.3 & 7.0 & 6.4 & 0.31 \\
\hline
\end{tabular}

Note: Time was measured from when an animal became recumbent as a result of the immobilisation.

$\mathrm{SE}$, standard error.

TABLE 1b: Species comparison of arterial blood $\mathrm{pH}$, lactate in $\mathrm{mmol} / \mathrm{L}$ and glucose in $\mathrm{mmol} / \mathrm{L}$ over time and standard error during immobilisation, with etorphine $0.09 \mathrm{mg} / \mathrm{kg}$ and thiafentanil $0.09 \mathrm{mg} / \mathrm{kg}$, of blesbok (Damaliscus pygargus phillipsi) and impala (Aepyceros melampus) respectively.

Variable Species Time after recumbence with thiafentanil in minutes SE

\begin{tabular}{llcccccc} 
& & $\mathbf{5}$ & $\mathbf{1 0}$ & $\mathbf{1 5}$ & $\mathbf{2 0}$ & $\mathbf{3 0}$ & \\
\cline { 3 - 6 } $\mathrm{nH}$ & Blesbok & 7.44 & 7.47 & 7.47 & 7.48 & 7.49 & 0.005 \\
& Impala & 7.27 & 7.31 & 7.33 & 7.35 & 7.40 & 0.007 \\
\multirow{2}{*}{ Lactate } & Blesbok & 1.2 & 0.9 & 0.8 & 0.7 & 0.5 & 0.22 \\
& Impala & 5.3 & 4.4 & 3.5 & 2.7 & 1.7 & 0.26 \\
\multirow{2}{*}{ Glucose } & Blesbok & 4.5 & 4.3 & 4.2 & 4.2 & 4.5 & 0.11 \\
& Impala & 8.8 & 9.0 & 8.8 & 8.6 & 8.1 & 0.31 \\
\hline
\end{tabular}

Note: Time was measured from when an animal became recumbent as a result of the immobilisation.

$\mathrm{SE}$, standard error.

respiratory depression. These findings have implications for the use of immobilising agents in the field and in different species.

Both species of antelope were successfully immobilised for 40 min with both opioids, using doses of nearly double the dose used when either opioid is combined with a tranquilliser or sedative (Kock \& Burroughs 2012).

Time to recumbence is an important factor under field conditions. Shorter time to recumbence reduces exposure to stressors and facilitates faster retrieval of the animal. A short time to recumbence also lessens the risk of animals disappearing or being attacked by herd members or predators whilst the drugs are taking effect. Therefore, the significantly shorter time to recumbence measured in impala when immobilised with thiafentanil in this experiment is of great clinical relevance. However, this factor must be weighed up against the severe adverse cardiopulmonary effects that this drug induces when a clinician decides to use it in the field. Importantly, this shorter time to recumbence does not seem to be ubiquitous in antelope as there was no difference in this variable when the two opioids were compared in the blesbok.

A further important difference, from a clinical perspective, between the two species was the heart rate. In blesbok treated with opioids, the heart rate was much slower (means measured between 36 beats $/ \mathrm{min}$ and 45 beats $/ \mathrm{min}$ ) than the mean heart rate that was measured in awake blesbok at rest (104 beats/min) (Du Plessis 2008). This could be interpreted as classic reflex bradycardia as a result of opioid-induced 
vasoconstriction and hypertension. Resting heart rates in impala are not known. However, in sheep and goats, which are similar in size to impala, resting heart rate is 70-110 beats / min (Izwan et al. 2018; Meyer et al. 2015; Sjaastad, Sand \& Hoove 2016). In contrast to blesbok, impala during the first 10 min developed a higher heart rate which showed wide variation between individuals and also over time (Figure 1a). Species differences in domestic and wild ungulates with regard to the effects of opioids on the heart rate have been reported previously (Harthoorn 1967; Izwan et al. 2018). In a comparative experiment between sheep and goats, sheep developed a significantly elevated heart rate with etorphine treatment, whilst the same treatment did not affect the heart rate of goats. At the same time, the stroke volume in sheep decreased and therefore the elevated heart rate did not result in changes in cardiac output (Izwan et al. 2018).

Despite the species difference in heart rate, both species developed an elevated MAP with both opioids. This elevation was more severe when thiafentanil was used, with mean MAP values of $136 \mathrm{mmHg}$ and $140 \mathrm{mmHg}$ for blesbok and impala respectively (Figure $1 \mathrm{~b}$ ). The MAP of most healthy ruminants should measure around $115 \mathrm{mmHg}$, irrespective of body size (Prothero 2015). In a field setting, heart rate and blood pressure are important variables as they may influence the choice of sedatives or tranquillisers to be combined with an opioid for immobilisation. For example, it is common practice amongst wildlife veterinarians to combine etorphine with the butyrophenone derivative azaperone as it is a tranquilliser but also causes vasodilation and has anti-hypertensive effects (Kock \& Burroughs 2012). This study highlights the fact that opioids have profound cardiovascular effects that need to be studied in more detail to understand their full physiological effects, reveal their species-specific risks and understand how additive drugs like sedatives and tranquillisers alter these.

Du Plessis (2018) reported a mean respiratory rate of recumbent resting blesbok of 13 breaths $/ \mathrm{min}$, and for standing blesbok a rate of 20 breaths/min. The respiratory rate of impala at rest has been reported as $20.0 \pm 8$ breaths / min (Cheney \& Hattingh 1987). Blood gas values for sheep and goats at rest were measured by Ismail, Jawasreh and AlMajali (2010) who reported a mean $\mathrm{PaCO}_{2}$ of $41 \pm 2.5$ for sheep and $40 \pm 7$ for goats. Impala, especially at the start of the monitoring period, displayed a low respiratory rate and hypercapnia $\left(\mathrm{PaCO}_{2}\right.$ means $=51 \mathrm{mmHg}$ [etorphine] and $52 \mathrm{mmHg}$ [thiafentanil]) with both opioid treatments. Impala also suffered from severe hypoxaemia $\left(\mathrm{PaO}_{2}\right.$ means $=$ $53 \mathrm{mmHg}$ [both drugs]).

$\mathrm{PaCO}_{2}$ values of blesbok (means $=45 \mathrm{mmHg}$ [etorphine] and $41 \mathrm{mmHg}$ [thiafentanil]) were within the upper physiological range of conscious small ruminants (Ismail et al. 2010), indicating adequate ventilation during immobilisation. Despite adequate ventilation, blesbok suffered from moderate hypoxaemia with thiafentanil (mean $\mathrm{PaO}_{2} 61 \mathrm{mmHg}$ to $68 \mathrm{mmHg}$ ) and severe hypoxaemia with the etorphine treatment (mean $\mathrm{PaO}_{2} 51 \mathrm{mmHg}$ to $54 \mathrm{mmHg}$ ) (Figure 2b, c). Possible reasons for hypoxaemia in this case can be explained by looking at the A-a gradient, which was elevated. In the literature, A-a gradients for small ruminants at rest were reported between $20 \mathrm{mmHg}$ and $25 \mathrm{mmHg}$ (Izwan et al. 2018; Meyer et al. 2006). Therefore, the mean A-a gradients of the blesbok as well as the impala treated with etorphine should be considered elevated as they measured 37 and $35 \mathrm{mmHg}$ respectively. This finding indicates that etorphine caused an equally elevated A-a gradient in both species. Thiafentanil, in contrast, caused a more severe A-a gradient elevation in impala (mean = $33 \mathrm{mmHg}$ ) compared to blesbok (mean $=28 \mathrm{mmHg}$ ). A ventilation-perfusion mismatch or right-left shunting of lung portions might have been the cause for inadequate oxygen diffusion indicated by the elevated A-a gradients (Fahlman et al. 2016; Meyer et al. 2015). Opioid-induced pulmonary vasoconstriction, resulting in pulmonary hypertension, might have also led to inadequate oxygen diffusion as a result of pulmonary congestion and/or oedema. Vasoconstriction could have also caused a faster blood flow which might have hindered gas exchange, as capillary blood might have passed the alveoli too fast to enable effective oxygen diffusion (Hattingh et al. 1994; Meyer et al. 2015). Furthermore, opioid-induced hypermetabolism (Buss et al. 2018) may have increased systemic oxygen extraction which possibly could have also increased the A-a gradient.

Clearly, if the respiratory rate was the only assessment of respiration, then hypoxaemia in blesbok under etorphine immobilisation would have been overlooked. The measurement of blood gases, although expensive and not always practical to use in the field, should therefore not be underestimated as an important monitoring tool.

Initially elevated lactate in the impala could have been associated with an initial exaggerated stress response of these animals to the capture procedure. A stress response would lead to an increased metabolism and therefore increase the oxygen demand, further compounding the hypoxaemia (Buss et al. 2018). The assumption that impala not only suffered from hypoxaemia due to opioid-induced respiratory compromise but also experienced a stress response is supported by the elevated glucose and an initially raised heart rate (Hattingh 1988). Blesbok, in contrast, did not show signs of such a severe initial stress response.

\section{Implications}

Impala seem to be more fractious in nature compared to blesbok and a stress response, coupled with a greater sensitivity to opioid-induced respiratory compromise, may explain why impala are more at risk and considered to be one of the more challenging species to immobilise. Not only are they a small and fragile target to dart but the severe respiratory disturbances, coupled with stress-related physiological derangements, can also be fatal if not immediately addressed. Furthermore, the time to recumbence induced by thiafentanil 
and etorphine differed in impala, and this should be taken into consideration when the appropriate opioid is chosen for the capture of this species.

In contrast, there was no difference in time to recumbence between the opioids in blesbok. Also, in blesbok, a heart rate lower than the resting heart rate can be expected when animals are immobilised with these opioids. This lower heart rate is likely a baroreceptor reflex to opioid-induced vasoconstriction and hypertension. Heart rate, respiratory rate and blood gas variables did not differ as much over the monitoring time in blesbok as was observed in impala. Furthermore, hypoxaemia and hypercapnia in the immobilised blesbok were not as severe as in impala.

Impala, due to their availability and presence in many zoos, have been commonly studied to understand the physiological effects of immobilising drugs. However, as this study indicates, the response to immobilising drugs is not uniform across all antelope species. Therefore, the practice of only using impala for such studies may result in misleading perceptions. Standardised monitoring and data analysis, from multiple antelope species immobilised during routine management procedures, should be undertaken in the future in order to better understand the physiological effects of the drugs used, and enable more clinically relevant, species-specific recommendations for immobilisation.

\section{Study limitations}

The small sample size is acknowledged as a limitation of this study. However, due to logistics, conservation status and ethical concerns, experiments in wildlife are often carried out with small numbers of 6 to 12 animals (Meyer et al. 2018; Pfitzer et al. 2019b; Zeiler \& Meyer 2017a). Only healthy, adult animals which were adapted to captivity were part of this experiment. In a field situation, drug doses might have to be adjusted according to the physiological status of the animals, such as size, age, nutritional status and pregnancy. For logistical and animal welfare reasons, only females were used in this study. Females may have slightly different drug and stress-related responses compared to males; however, these differences need to be confirmed.

\section{Conclusion}

This experiment confirms the initial hypothesis that significantly different, species-specific physiological responses to opioid immobilising drugs exist between blesbok and impala. The most profound difference was that blesbok seem less affected by respiratory compromise than impala. Impala developed severe hypoxaemia, which is not only due to opioid-induced hypoventilation but also likely due to the impairment of oxygen diffusion as well as hypermetabolism. Some of the changes observed in impala might also be strongly associated with a species-specific stress response to capture, rather than just the actions of the opioids themselves. Extrapolation of immobilisation results from one species of African ungulate to another is not recommended, given the significant differences in the way that these two species responded to the immobilisation.

\section{Acknowledgements}

The study was supported by staff and students of Wildlifevets.com. We also thank Jane Speijers for the statistical evaluation. This article forms part of the $\mathrm{PhD}$ thesis of Silke Pfitzer. Reference to this submission for publication will be made in the appropriate chapter.

\section{Competing interests}

J.P. Raath, one of the investigators, has a financial interest in Wildlife Pharmaceuticals Pty Ltd, the company that also supported this project financially. However, we do not believe that this would have inappropriately influenced the analysis or writing of this article.

\section{Authors' contributions}

S.P. was the primary investigator, collected data, wrote the article, and submitted the article, S.P. and M.L. was responsible for the experimental design and execution. and analysis of the article. M.L. was co-author and PhD supervisor of S.P. and assisted with statistical and data analysis. L.L. and J.P.R. attended to the experimental design and execution, manuscript editing and statistical analysis. K.W. and R.V.-H. assisted with the article editing and analysis. L.R.C.M. assisted with experimental design and execution, data analysis, manuscript editing, and was the senior author on the article.

\section{Funding information}

This study was financially supported by the research fund of the Wildlife Group of the South African Veterinary Association as well as by funding from Murdoch University and Wildlife Pharmaceuticals SA (Pty) Ltd.

\section{Data availability statement}

Data that support the results of this study is made available in the article. Additional raw data that were generated in this study can be supplied on request by the corresponding author.

\section{Disclaimer}

The views and opinions expressed in this article are those of the authors and do not necessarily reflect the official policy or position of any affiliated agency of the authors.

\section{References}

Buss, P., Miller, M., Fuller, A., Haw, A., Stout, E., Olea-Popelka, F. et al., 2018, 'Postinduction butorphanol administration alters oxygen consumption to improve blood gases in etorphine-immobilized white rhinoceros', Veterinary Anaesthesia and Analgesia 45, 57-67. https://doi.org/10.1016/j.vaa.2017.03.008

Chen, L., Qiu, Q., Jiang, Y., Wang, K., Lin, Z., Li, Z. et al., 2019, 'Large-scale ruminant genome sequencing provides insights into their evolution and distinct traits', Science Magazine Digital, viewed June 2019, from www.sciencemagazinedigital.org 
Cheney, C.S. \& Hattingh, J., 1987, 'Effects of chemical immobilisation on the blood composition of impala (Aepyceros melampus) Lichtenstein', Journal of the South African Veterinary Association 59(1), 13-18.

Du Plessis, D., 2018, The potential of midazolam for use as sedative for blesbok (Damaliscus pygargus phillipsi), Stellenbosch University, viewed 1 January 2020 from http://scholar.sun.ac.za

Fahlman, A., Edner, A., Wenger, S., Foggin, C. \& Nyman, G., 2016, 'Pulmonary gas exchange and acid-base status during immobilisation of black rhinoceroses (Diceros bicornis) in Zimbabwe', Journal of the South African Veterinary Association 87, a1328. https://doi.org/10.4102/jsava.v87i1.1328

Hernandez Fernandez, M. \& Vrba, E.S., 2005. 'A complete estimate of the phylogenetic relationships in Ruminantia: A dated species-level supertree of the extant ruminants.' Biological Reviews of the Cambridge Philosophical Society, 80(2), 269-302. https://doi.org/10.1017/S1464793104006670

Fitte, A., 2017, 'Determination of the pathophysiological consequences of capture and capture-induced hyperthermia in blesbok (Damaliscus pygargus phillipsi)' MSc thesis, University of Pretoria, Pretoria.

Furstenburg, D., 2016a, 'Blesbok (Damaliscus pygargus phillipsi), bontebok (Damaliscus pygargus pygargus)', in P. Oberem \& P. Oberem (eds.), The New Game Rancher, pp. 196-204, Queenswood, Briza.

Furstenburg, D., 2016b, 'Impala (Aepyceros melampus)', in P. Oberem \& P. Oberem (eds.), The New Game Rancher, pp. 217-225, Queenswood, Briza.

Harthoorn, A.M., 1967, 'Comparative pharmacological reactions of certain wild and domestic mammals to thebaine derivatives in the M-series of compounds', Federation Proceedings 26(4), 1251-1261, Queenswood.

Hattingh, J., 1988, 'Comparative quantitation of the physiological response to acute stress in impala and roan antelope', Comparative Biochemistry and Physiology Part A 89(4), 547-551. https://doi.org/10.1016/0300-9629(88)90831-6

Hattingh, J., Knox, C.M. \& Raath, J.P., 1994, 'Arterial blood pressure and blood gas composition of white rhinoceros under etorphine anaesthesia', Journal of the South African Veterinary Association 24, 12-14.

Heard, D., Wilmer, N.W., Buss, D. \& Kollias, G.V., 1996, 'Comparative cardiopulmonary effects of intramuscularly administered etorphine and carfentanil in goats', American Journal of Veterinary Research 57(1), 89-96.

Hernandez Fernandez, M. \& Vrba, E.S., 2005, 'A complete estimate of the phylogenetic relationships in Ruminantia: A dated species-level supertree of the extant ruminants', Biological Reviews of the Cambridge Philosophical Society 80 269-302. https://doi.org/10.1017/S1464793104006670

Ismail, Z.B., Jawasreh, K. \& Al-Majali, A., 2010, 'Effect of xylacine-ketamine-diazepam anaesthesia on certain clinical and arterial blood gas parameters in sheep and goats', Comparative Clinical Pathology 19, 11-14. https://doi.org/10.1007/ s00580-009-0896-6

Izwan, A., Snelling, E.P., Seymour, R.S., Meyer, L.C.R., Fuller, A., Haw, A. et al., 2018, 'Ameliorating the adverse cardiorespiratory effects of chemical immobilization by inducing general anaesthesia in sheep and goats: Implications for physiological studies of large wild mammals', Journal of Comparative Physiology B: Biochemical, Systemic and Environmental Physiology B 188, 991-1003, https://doi.org/ $10.1007 / \mathrm{s} 00360-018-1184-z$

Janssen, D.L., Swan, G.E., Raath, J.P., McJames, S.W., Allen, J.L., De Vos, V. et al., 1993, Immobilization and physiologic effects of the narcotic A-3080 in impala (Aepyceros melampus)', Journal of Zoo and Wildlife Medicine 24(1), 11-18.

Kock, M.D. \& Burroughs, R.E., 2012, Chemical and physical restraint of wild animals, 2nd edn., International Wildlife Veterinary Services, Pretoria.

Meyer, L.C.R., Fuller, A. \& Mitchell, D., 2006, 'Zacopride and 8-OH-DPAT reverse opioidinduced respiratory depression and hypoxia but not catatonic immobilization in goats', American Journal of Physiology: Regulatory, Integrative and Comparative Physiology 290(2), R405-R413. https://doi.org/10.1152/ajpregu.00440.2005
Meyer, L.C.R., Fuller, A., Hofmeyer, M., Buss, P., Miller, M. \& Haw, A., 2018, 'Use of butorphanol and diprenorphine to counter respiratory impairment in the immobilised white rhinoceros (Ceratotherium simum)', Journal of the South immobilised white rhinoceros (Ceratotherium simum), Journal of the South
African Veterinary Association 89(0), a1683. https://doi.org/10.4102/jsava. v89i0.1683

Meyer, L.C.R., Hetem, R.S., Fick, L.G., Matthee, A., Mitchell, D. \& Fuller, A., 2008 'Thermal, cardiorespiratory and cortisol responses of impala (Aepyceros melampus) to chemical immobilisation with 4 different drug combinations', melampus) to chemical immobilisation with 4 different drug combinations,
Journal of the South African Veterinary Association 79(3), 121-129. https://doi. Journal of the South African
org/10.4102/jsava.v79i3.258

Meyer, L.C.R., Hetem, R.S., Fick, L.G., Mitchell, D. \& Fuller, A., 2010, 'Effects of serotonin agonists and doxapram on respiratory depression and hypoxemia in etorphine-immobilized impala (Aepyceros melampus)', Journal of Wildlife Diseases 46(2), 514-524. https://doi.org/10.7589/0090-3558-46.2.514

Meyer, L.C.R., Hetem, R.S., Mitchell, D. \& Fuller, A., 2015, 'Hypoxia following etorphine administration in goats (Capra hircus) results more from pulmonary hypertension than from hypoventilation', BMC Veterinary Research 11, 1-9. https://doi.org/ 10.1186/s12917-015-0337-5

O'Dell, J.H., Kock, M.D., Thompson, P.N. \& Meyer, L.C.R., 2017, 'Minimum effective naltrexone dose to antagonise etorphine immobilisation and prevent the complications of renarcotisation in domestic goats', Veterinary Record 181(18), 481. https://doi.org/10.1136/vr.104435

Perrin, K.L., Denwood, M.J., Grøndahl, C., Nissen, P. \& Bertelsen, M.F., 2015, 'Comparison of etorphine-acepromazine and medetomidine-ketamine anaesthesia in captive impala (Aepyceros melampus)', Journal of Zoo and Wildlife Medicine 46(4), 870-879. https://doi.org/10.1638/2015-0114.1

Pfitzer, S., Woodward, A.P., Laubscher, L., Warren, K., Vaughan-Higgins, R., Raath, J.P. et al., 2019a, 'Pharmacokinetics and bioavailability after intramuscular injection of the $5-\mathrm{HT}^{1 \mathrm{~A}}$ serotonin agonist R-8-hydroxy-2-(di-n-propylamino) tetralin (8-OH-DPAT) in domestic goats (Capra aegagrus hircus)', Journal of Veterinary Pharmacology and Therapeutics 42(3), 251-257. https://doi.org/10.1111/ jvp.12741

Pfitzer, S., Laubscher, L., Meyer, L., Warren, K., Vaughan-Higgins, R., Raath, J.P. et al., $2019 \mathrm{~b}$, 'Dose-effect study of the serotonin agonist R-8-OH-DPAT on opioidinduced respiratory depression in blesbok (Damaliscus pygargus philipsi) and impala (Aepyceros melampus)', Veterinary Anaesthesia and Analgesia 46(6), 796-806. https://doi.org/10.1016/j.vaa.2019.06.006

Prothero, J.W., 2015, The design of mammals: A scaling approach, p. 116, Cambridge University Press, Cambridge.

SABS (South African Bureau of Standards), 2004, Holding pens for temporary housing of animals, SANS 1884-1:2004. ISBN 0-626-15443-X.

Sawicka, J., Fuller, A., Fick, L.G., Hetem, R.S. \& Meyer, L.C.R., 2015, 'Efficacy of different cooling methods for capture-induced hyperthermia in antelope', African Journal of Wildlife Research 45(1), 100-110. https://doi.org/10. 3957/056.045.0111

Sjaastad, O.V., Sand, O. \& Hoove, K., 2016, Physiology of domestic animals, 3rd edn., Scandinavian Veterinary Press, Oslo.

Zeiler, G.E. \& Meyer, L.C.R., 2017a, 'Comparison of thiafentanil-medetomidine to etorphine-medetomidine immobilisation of impalas (Aepyceros melampus)', Journal of the South African Veterinary Association 88(1), 1-8. https://doi. Journal of the South African
org/10.4102/jsava.v88i0.1520

Zeiler, G.E. \& Meyer, L.C.R., 2017b, 'Blood acid-base status in impala (Aepyceros melampus) immobilised and maintained under total intravenous anaesthesia using two different drug protocols', BMC Veterinary Research 13(1), 1-11. https:// using two different drug protocols',
doi.org/10.1186/s12917-017-1163-8 